\title{
Desulfurization of heavy oil
}

\author{
Rashad Javadli • Arno de Klerk
}

Received: 23 November 2011 / Accepted: 2 February 2012/Published online: 1 March 2012

(C) The Author(s) 2012. This article is published with open access at Springerlink.com

\begin{abstract}
Strategies for heavy oil desulfurization were evaluated by reviewing desulfurization literature and critically assessing the viability of the various methods for heavy oil. The desulfurization methods including variations thereon that are discussed include hydrodesulfurization, extractive desulfurization, oxidative desulfurization, biodesulfurization and desulfurization through alkylation, chlorinolysis, and by using supercritical water. Few of these methods are viable and/or efficient for the desulfurization of heavy oil. This is mainly due to the properties of the heavy oil, such as high sulfur content, high viscosity, high boiling point, and refractory nature of the sulfur compounds. The approach with the best chance of leading to a breakthrough in desulfurization of heavy oil is autoxidation followed by thermal decomposition of the oxidized heavy oil. There is also scope for synergistically employing autoxidation in combination with biodesulfurization and hydrodesulfurization.
\end{abstract}

Keywords Desulfurization - Heavy oil · Bitumen · Hydrodesulfurization (HDS) · Oxidative desulfurization (ODS) · Biodesulfurization (BDS) · Autoxidation

R. Javadli $(\bowtie) \cdot$ A. de Klerk

Department of Chemical and Materials Engineering,

University of Alberta, Edmonton,

AB T6G 2V4, Canada

e-mail: javadli@ualberta.ca

Present Address:

R. Javadli

ConocoPhillips Canada,

Fort McMurray, AB, Canada

\section{Introduction}

Refining of crude oil to final products requires desulfurization of the oil. Fuel specifications that govern transportation fuels have over the years become increasingly stringent with respect to sulfur content. Many petrochemical products are likewise produced to be almost sulfur-free. The removal of sulfur from oil is consequently one of the central conversion requirements in most refineries and the price (and processing cost) of a crude oil is influenced by its sulfur content.

The concentration and nature of the sulfur-containing compounds change over the boiling range. The amount of sulfur in a distillation fraction increases with an increase in boiling range (Table 1) (Heinrich and Kasztelaan 2001), with the heaviest fraction containing the most sulfur. The sulfur compounds become more refractory with increasing boiling point, as the dominant compound class changes from thiols, sulfides, and thiophene in the naphtha to substituted benzothiophenic compounds in the distillate (Table 2) (Weast 1988). In the vacuum gas oil and vacuum residue, the sulfur is contained mainly in compounds of the dibenzothiophene family. The chemical nature of the sulfur has direct bearing on its removal. Desulfurization of compounds that contain aliphatic sulfur, i.e. thiols and sulfides, is easier than desulfurization of compounds that contain aromatic sulfur, i.e. thiophenics.

Hydrodesulfurization (HDS) in combination with carbon rejection technologies, such as coking and fluid catalytic cracking (FCC), are the main technologies industrially employed for the desulfurization of heavy oil (Rana et al. 2007). Although these technologies are quite capable of desulfurizing heavy oil, their carbon footprints are substantial. All of these technologies, including the production of hydrogen that is needed for HDS, involve high-temperature processing. The refining cost (financial and environmental) increases as heavier and more sulfur-rich crude 
Table 1 Distribution of sulphur compounds over the distillation range of a crude oil with total sulfur content of $1.2 \%$

a Benzothiophenes, dibenzothiophenes and heavy sulfides

Table 2 Physical properties of selected sulfur-containing compounds

${ }^{\text {a }}$ Not reported in reference

\begin{tabular}{llllll}
\hline Distillation range $\left({ }^{\circ} \mathrm{C}\right)$ & Sulfur content $(\%)$ & \multicolumn{4}{l}{ Sulfur compound distribution $(\%)$} \\
\cline { 3 - 6 } & & Thiols & Sulfides & Thiophenes & Other $^{\text {a }}$ \\
\hline $70-180$ (naphtha) & 0.02 & 50 & 50 & Trace & - \\
$160-240$ (kerosene) & 0.2 & 25 & 25 & 35 & 15 \\
$230-350$ (distillate) & 0.9 & 15 & 15 & 35 & 35 \\
$350-550$ (vacuum gas oil) & 1.8 & 5 & 5 & 30 & 60 \\
$>550$ (vacuum residue) & 2.9 & Trace & Trace & 10 & 90 \\
\hline
\end{tabular}

\begin{tabular}{llcc}
\hline Compound & $\begin{array}{l}\text { Normal boiling } \\
\text { point }\left({ }^{\circ} \mathrm{C}\right)\end{array}$ & $\begin{array}{l}\text { Melting } \\
\text { point }\left({ }^{\circ} \mathrm{C}\right)\end{array}$ & $\begin{array}{c}\text { Density at } 20{ }^{\circ} \mathrm{C} \\
\left(\mathrm{kg} \mathrm{m}^{-3}\right)\end{array}$ \\
\hline 1-Ethanethiol (ethyl mercaptan) & 35 & -144.4 & 839.1 \\
Dimethyl sulfide & 37.3 & -98.3 & 848.3 \\
1-Propanethiol (propyl mercaptan) & 67 & -113.3 & 841.1 \\
Thiophene & 84.2 & -38.2 & 1064.9 \\
Diethyl sulfide & 92.1 & -103.8 & 836.2 \\
1-Butanethiol (butyl mercaptan) & 98.4 & -115.7 & 833.7 \\
Dimethyl disulfide & 109.7 & -84.7 & 1062.5 \\
Tetrahydrothiophene (thiolane) & 121.1 & -96.2 & 998.7 \\
Dipropyl sulfide & 142.4 & -102.5 & 837.7 \\
Thiophenol & 168.7 & -14.8 & 1076.6 \\
Dibutyl sulfide & 185 & -79.7 & 838.6 \\
Benzothiophene (thianaphthene) & 221 & 32 & 1148.4 \\
Dibutyl disulfide & 226 & $-{ }^{\mathrm{a}}$ & 938.3 \\
Dibenzothiophene & 332 & 99 & $-{ }^{\mathrm{a}}$ \\
\hline
\end{tabular}

oils are being processed. Alternative desulfurization pathways are therefore of interest.

There are many reviews on desulfurization in general, e.g. Babich and Moulijn (2003), Ito and Van Veen (2006) and Pawelec et al. (2011). Desulfurization is usually discussed in terms of sulfur removal from lighter refinery cuts, such as naphtha, distillate, and light vacuum gas oil fractions. The purpose of the present review paper is to provide an overview of the different conversion strategies that can be employed for desulfurization of heavy oils. Each desulfurization method will be assessed to determine its applicability to heavy oil in general and where possible, with focus on heavy Canadian oilsands-derived bitumen. As the reader will see from the subsequent discussion, many of the desulfurization methods proposed in literature are only useful for the desulfurization of lighter fractions and cannot be employed for heavy oil. This review will assess opportunities for heavy oil desulfurization specifically.

\section{Sulfur in crude oil}

Sulfur is the most abundant element in petroleum after carbon and hydrogen. The average sulfur content varies from 0.03 to 7.89 mass\% in crude oil (Mehran et al. 2007). The sulfur compounds can be found in two forms: inorganic and organic. Inorganic sulfur, such as elemental sulfur, $\mathrm{H}_{2} \mathrm{~S}$ and pyrite can be present in dissolved or suspended form (Agarwal and Sharma 2010). Organic sulfur compounds such as thiols, sulfides, and thiophenic compounds represent the main source of sulfur found in crude oil. Some of the important classes of organic sulfur compounds are shown in Fig. 1.

Crude oils with higher viscosities and higher densities usually contain higher amounts of more complex sulfur compounds. The aliphatic acyclic sulfides (thioethers) and cyclic sulfides (thiolanes) are easy to remove during a hydrodesulfurization process or by thermal treatment. On the other hand, sulfur contained in aromatic rings, such as thiophene and its benzologs (e.g. benzothiophene, dibenzothiophene, benzonaphthothiophene) are more resistant to sulfur removal by hydrodesulfurization and thermal conversion (Gray et al. 1995).

Sulfur compounds in oilsand-derived bitumen

Processing bitumen extracted from oil sands is challenging due to high viscosity, high density, and high concentration 
Fig. 1 Important classes of sulfur-containing compounds in crude oil $(\mathrm{R}=$ alkyl $)$

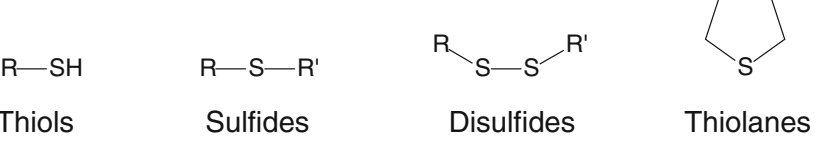

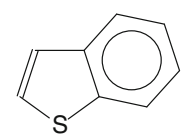

Benzothiophenes

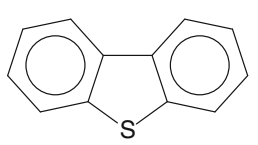

Dibenzothiophenes

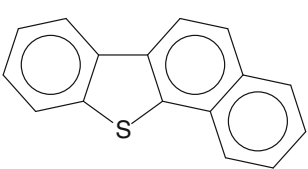

Benzonaphtothiophenes

Table 3 Selected properties of two Canadian oilsands-derived bitumens in comparison with West Texas Intermediate (WTI) as a benchmark light crude oil

\begin{tabular}{llll}
\hline Property & $\begin{array}{l}\text { Cold Lake } \\
\text { bitumen }\end{array}$ & $\begin{array}{l}\text { Athabasca } \\
\text { bitumen }\end{array}$ & $\begin{array}{l}\text { Light crude } \\
\text { oil (WTI) }\end{array}$ \\
\hline Sulfur content (mass\%) & 4.4 & 4.9 & 0.3 \\
Nitrogen content $(\mathrm{mass} \%)$ & 0.4 & 0.5 & 0.08 \\
Metals content $\left(\mu \mathrm{g} \mathrm{g}^{-1}\right)$ & 220 & 280 & 3 \\
Density $\left(\mathrm{kg} \mathrm{m}^{-3}\right)$ & 1,000 & 1,007 & 821 \\
$\left({ }^{\circ}\right.$ API) & 10 & 9 & 40.8 \\
Viscosity at $40{ }^{\circ} \mathrm{C}\left(\mathrm{mm}^{2} \mathrm{~s}^{-1}\right)$ & 5,000 & 7,000 & 4 \\
Vacuum residue, $>524{ }^{\circ} \mathrm{C}(\mathrm{vol} \%)$ & 52 & 52 & 12.9 \\
\hline
\end{tabular}

of heteroatoms (Table 3) (Gray et al. 1991; Gray 2010) which is considerably higher than that of a typical benchmark light crude oil. Reliable data on the oxygen content of Canadian bitumen is more limited, due to difficulty in obtaining reasonable results. The most important oxygen compounds are the acid groups in bitumen. Bitumen has a total oxygen content of $1.1 \pm 0.3$ mass $\%$, and approximately $25 \%$ of the total oxygen is present as carboxylic acids groups. Athabasca bitumen has a total acid number of around $5.5 \mathrm{mg} \mathrm{KOH} \mathrm{g}^{-1}$ (Gray 2010).

Bitumen contains no elemental sulfur or hydrogen sulfide. Analysis of Cold Lake bitumen by X-ray absorption near-edge structure spectroscopy (XANES) showed that bitumen contains more aromatic sulfur (3.05 mass $\%)$ and less aliphatic sulfur (1.86 mass\%). In other words, $62 \%$ of the total sulfur content of oilsands derived bitumen is aromatic and 38\% is aliphatic (Brons and Yu 1995).

Considerable effort has gone into the identification of sulfur compounds present in heavy oils, including oilsandsderived bitumen (Purcell et al. 2007; Donald et al. 2008; Panda et al. 2009; Shi et al. 2010; Liu et al. 2010). The reported molecular weight of sulfur compounds in the oilsands bitumen varies from 200 to $700 \mathrm{~m} / z$ (Shi et al. 2010), although this is a contentious subject. The relative abundance of species containing one, two, or three sulfur atoms per compound $\left(\mathrm{S}_{1}, \mathrm{~S}_{2}\right.$ and $\mathrm{S}_{3}$ species) are 74,11 , and $1 \%$, respectively. Sulfur also occurs in combination with other heteroatoms. The order of relative abundance of sulfur in sulfur-only and mixed heteroatom-containing species is (Shi et al. 2010): $S_{1}>S_{2}>$ $\mathrm{S}_{1} \mathrm{O}_{1}>\mathrm{S}_{1} \mathrm{O}_{2}>\mathrm{S}_{1} \mathrm{~N}_{1} \approx \mathrm{S}_{2} \mathrm{O}_{1}>\mathrm{S}_{3}$.
Compounds containing only a single sulfur atom without any other heteroatoms $\left(S_{1}\right)$, such as benzothiophenes and dibenzothiophenes, are the dominant sulfur compounds in oil sands-derived bitumen (Purcell et al. 2007; Panda et al. 2009; Shi et al. 2010). It is likely that the $\mathrm{S}_{1} \mathrm{O}_{1}$ species are mainly sulfoxides and that the $\mathrm{S}_{1} \mathrm{O}_{2}$ species are mainly sulfones. These compounds are naturally occurring oxidation products of the crude oil (Sudipa et al. 1999). The $S_{2}$ and $S_{3}$ type species are more likely to be benzodithiophenes and conjugated benzothiophenes or dibenzothiophenes with two thiophenes or more, respectively (Fig. 2) (Shi et al. 2010; Liu et al. 2010).

\section{Desulfurization technologies}

\section{Hydrodesulfurization (HDS)}

Hydrodesulfurization is the most commonly used method in the petroleum industry to reduce the sulfur content of crude oil. In most cases HDS is performed by co-feeding oil and $\mathrm{H}_{2}$ to a fixed-bed reactor packed with an appropriate HDS catalyst. The standard HDS catalysts are NiMo/ $\mathrm{Al}_{2} \mathrm{O}_{3}$ and $\mathrm{CoMo} / \mathrm{Al}_{2} \mathrm{O}_{3}$, but there are many more types available. During HDS, the sulfur in the organosulfur compounds is converted to $\mathrm{H}_{2} \mathrm{~S}$.

The selection of one catalyst type over another is application dependent. Generally speaking NiMo-catalysts are more hydrogenating, whereas CoMo-catalysts are better at hydrogenolysis (Topsøe et al. 1996). CoMo-catalysts 
Fig. 2 Compound classes containing two $\left(\mathrm{S}_{2}\right)$ and three $\left(\mathrm{S}_{3}\right)$ sulfur atoms per compound

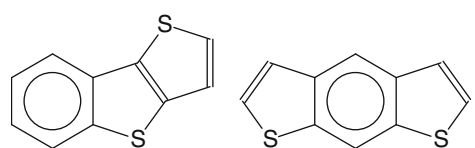

Benzodithiophenes

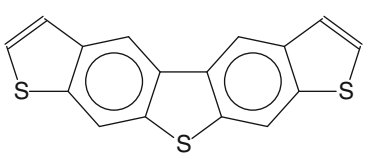

Conjugated benzothiophenes are consequently preferred for the HDS of unsaturated hydrocarbon streams, like that from fluid catalytic cracking (FCC), whereas NiMo-catalysts are preferred for fractions requiring extreme hydrogenation. NiMo catalysts are consequently more efficient for HDS of refractory compounds such as 4,6-dimethyldibenzothiophene (DMDBT) (Bataille et al. 2000). When hydrogen flow is not constraining, but contact time is limited, as is often the case in flow reactors, NiMo-catalysts are preferred, whereas CoMo-catalysts are sometimes more efficient in batch reactors (Lecrenay et al. 1997). Hydrotreating conditions typically range from 200 to $425^{\circ} \mathrm{C}$ and 1 to $18 \mathrm{MPa}$, the specific conditions depending on the degree of desulfurization required and the nature of the sulfur compounds in the feed.

Aliphatic sulfur compounds are very reactive and can be removed completely during HDS (Eqs. 1-3).

Thiols : $\mathrm{R}-\mathrm{SH}+\mathrm{H}_{2} \rightarrow \mathrm{R}-\mathrm{H}+\mathrm{H}_{2} \mathrm{~S}$

Sulfides : $\mathrm{R}_{1}-\mathrm{S}-\mathrm{R}_{2}+2 \mathrm{H}_{2} \rightarrow \mathrm{R}_{1}-\mathrm{H}+\mathrm{R}_{2}-\mathrm{H}+\mathrm{H}_{2} \mathrm{~S}$

Disulfides : $\mathrm{R}_{1}-\mathrm{S}-\mathrm{S}-\mathrm{R}_{2}+3 \mathrm{H}_{2}$

$$
\rightarrow \mathrm{R}_{1}-\mathrm{H}+\mathrm{R}_{2}-\mathrm{H}+2 \mathrm{H}_{2} \mathrm{~S}
$$

The sulfur contained in thiophenic rings is more difficult to remove. The lone pair electrons from sulfur participates in the $\pi$-electron structure of the conjugated $\mathrm{C}=\mathrm{C}$ system. The resonance stabilization is around $120-130 \mathrm{~kJ} \mathrm{~mol}^{-1}$, which is less than that of benzene $\left(160-170 \mathrm{~kJ} \mathrm{~mol}^{-1}\right)$ (Hochgesang 1952), but still sufficient to make HDS energetically demanding. Two pathways of desulfurization are distinguished (Fig. 3) (Babich and Moulijn 2003; Ho 2004). The least hydrogen intensive pathway is by hydrogenolysis. For the reasons mentioned before, resonance stabilization of the sulfur in the thiophene ring makes direct hydrogenolysis difficult and the main HDS pathway requires saturation of the aromatic ring before HDS can take place. However, the equilibrium concentration of the hydrogenated product is low, because there is significant driving force for aromatization by dehydrogenation.

Resonance stabilization of thiophene also prevents cracking and explains why most thiophenic sulfur compounds end up in forming coke during fluid catalytic cracking (Corma et al. 2001). Hydrocracking facilitates aromatic hydrogenation, which enables desulfurization by cracking and by hydrogenation. The use of hydrocracking catalysis with heavy oil is not to improve HDS, but in the hope of achieving selective ring opening to improve distillate quality (Santana et al. 2006).

Even though HDS is industrially employed for upgrading heavy oil, its effectiveness is undermined by the following properties of heavy oils:

(a) high metal content, which causes deposit formation and catalyst deactivation.

(b) Coking and fouling propensity, which results in catalyst deactivation.

(c) Molecular size, which limits access to smaller catalyst pores.

(d) Steric protection of thiophenic sulfur, making adsorption for HDS difficult.

\section{Extractive desulfurization}

Desulfurization via extraction depends on the solubility of the organosulfur compounds in certain solvents. It is a liquid-liquid extraction process and the two liquid phases must be immiscible. The elements of extractive desulfurization are shown in Fig. 4.

In the mixing tank the feedstock is mixed with the solvent and the organosulfur compounds are extracted into the solvent because of their higher solubility in the solvent. Then, in the separator section, the hydrocarbon is separated from the solvent. After separation the treated hydrocarbon with lower sulfur content can be processed further. During distillation the organosulfur compounds are separated from the solvent and the recovered solvent is recycled to the mixing tank.

Extractive desulfurization is an attractive method because of its straightforward industrial application, nonrequirement of $\mathrm{H}_{2}$, and moderate process conditions; the mixing tank can be operated at near-ambient conditions (Babich and Moulijn 2003). As a result, the feedstock is not chemically converted and the process is a purely physical extraction. However, there are a few pitfalls:

(a) The efficiency of extractive desulfurization is limited by the solubility of the organosulfur compounds in the solvent. So, appropriate solvent selection is very important for efficient desulfurization. Different types of solvents have been tried such as acetone, ethanol, and polyethylene glycols, which resulted in 50-90\% desulfurization depending on the number of extraction cycles of the process (Izumi and Tetsuo 1995; Paulino 1995). 
Fig. 3 Hydrogenation and hydrogenolysis pathways of hydrodesulfurization as illustrated by the desulfurization of dibenzothiophene
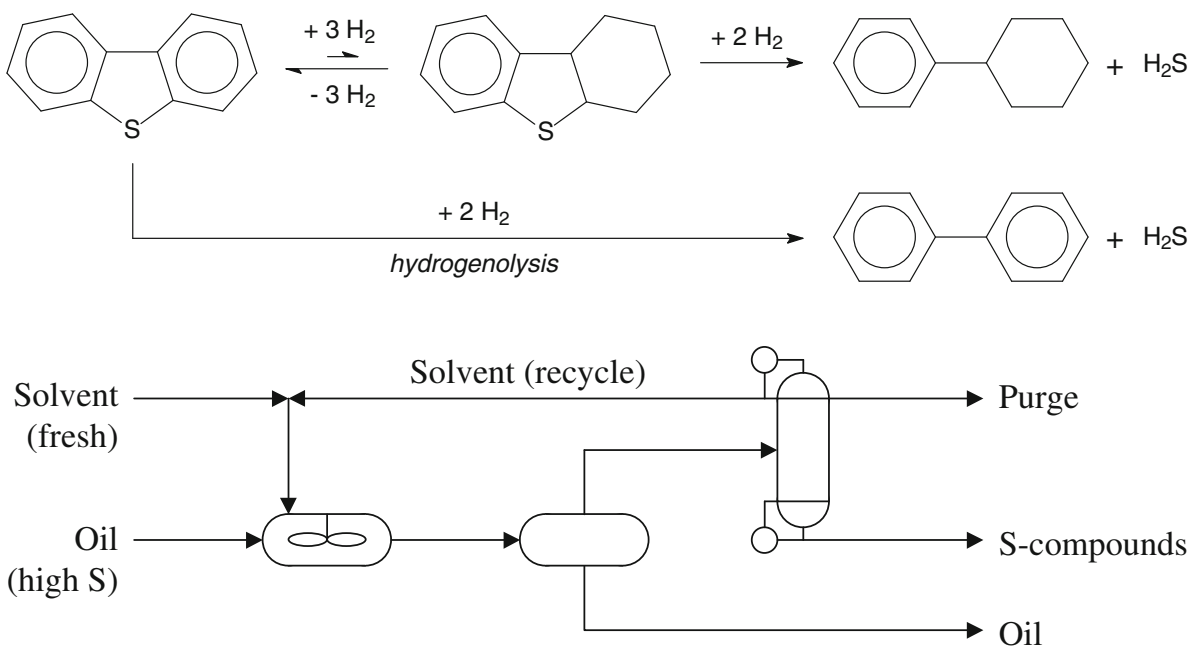

$\begin{array}{ccc}\text { Mixing tank } & \text { Separator } & \text { Distillation } \\ \text { (liquid-liquid } & \text { (phase } & \text { (solvent } \\ \text { extraction) } & \text { separation) } & \text { recovery) }\end{array}$
Fig. 4 General process for extractive desulfurization as illustrated by extraction with a low boiling solvent diesel oils. In the literature imidazolium-, pyridinium- or quinolinium-based ionic liquids with anions such as alkylsulfates, alkylphosphates, or halogen-containing anions are presented as the most appropriate ILs with good extraction characteristics (Seeberger and Jess 2010).

Ideal ionic liquids have a high distribution coefficient for sulfur compounds, a low cross solubility for the hydrocarbons, a low viscosity, and fast phase separation rate after mixing and extraction. Unfortunately, the performance of real ionic liquids for liquid-liquid extraction is less favorable.

Although ionic liquids have high distribution coefficient for model sulfur compounds, such as dibenzothiophene, in model mixtures, the distribution coefficient in real straight run distillate is rather low. In other words, ionic liquids are not ideal solvents for extractive desulfurization of real straight run distillates. In heavy oil the situation becomes worse. The efficiency of an extraction process with ionic liquids increases if the organosulfur compounds are previously oxidized to corresponding sulfoxides and sulfones, since oxidised sulfur compounds have much higher distribution coefficient.

Ionic liquids are high boiling solvents and recovery of extracted sulfur compounds is more challenging than with organic solvents. Some of the approaches that were proposed by Seeberger and Jess (2010), Haung et al. (2004), Bosmann et al. (2001) and Esser et al. (2004) are:

(a) Direct removal of sulfur compounds from ionic liquids by distillation. The boiling point of heavier organosulfur compounds, such as alkylated dibenzothiophenes, are high $\left(>340^{\circ} \mathrm{C}\right)$ and it would require vacuum distillation. Thus, this method is applicable only to desulfurization of lighter petroleum cuts.
The extractive desulfurization of fuels such as diesel oil by ionic liquids (ILs) as opposed to traditional organic solvents is an interesting alternative to provide ultra clean
The need to make use of a light solvent and the potential loss of solvent by dissolution in such a complex matrix as heavy oil erodes the cost effectiveness of extractive pro-

\section{Ionic liquid extraction}

cesses for desulfurization of heavy oil.

(b) In order to allow proper physical separation between the solvent and the oil, the two phases must be immiscible. The solvent should also have low equilibrium solubility in the oil to limit solvent loss during the process.

as possible to improve mixing and extraction. This is a problem with heavy oil, which requires extraction at elevated temperatures to reduce its viscosity. It also places a extraction may ha removed by distillation. During solvent recycling the concentration of these compounds will increase and a purge is necessary. 
(b) Sulfur compounds can be re-extracted with a lowboiling-point solvent. It requires an additional separation step though. First, the ionic liquid must be extracted for recycling and then the solvent used to clean the ionic liquid must be cleaned by separation of sulfur compounds during solvent by distillation.

(c) Sulfur compounds can be separated from sulfurloaded ionic liquids by addition of water. The distribution coefficient of sulfur compounds in ionic liquids decreases to almost zero if enough water is added to the system. The sulfur compounds, together with some light hydrocarbons that were extracted, can then be dissolved or form a second liquid phase in the water. The sulfur compounds may even precipitate. This strategy is more efficient if the sulfur compounds are oxidized. Before the ionic liquids can be recycled, the water must be removed. Water evaporation from ionic liquids is a crucial step in this process in terms of energy consumption. The multi-stage evaporation process (four-stage evaporation) at different temperatures and pressures was proposed to save energy (Seeberger and Jess 2010). The energy demand is comparable to the energy demand of traditional HDS if multi-stage evaporation is used.

Extractive desulfurization with ionic liquids shares many of the advantages previously cited for organic solvent extraction. Drawbacks such as the high cost and water sensitivity of some ionic liquids detract from its large-scale industrial application.

There are no reports on the extractive desulfurization to heavy oil. This is not surprising considering the difficulties even with straight run distillate desulfurization. Ionic liquid extraction is not feasible as desulfurization method for heavy oil.

\section{Adsorptive desulfurization}

Desulfurization by adsorption depends on the ability of a solid sorbent to selectively adsorb organosulfur compounds from the oil. The efficiency of this method depends on the properties of the sorbent material: selectivity to organosulfur compounds relative to hydrocarbons, adsorption capacity, durability, and regenerability. There are two approaches that can be taken for adsorptive desulfurization:

(a) Physical adsorption, where the sulfur compounds are not chemically altered by the separation. The energy that is required for regeneration depends on the strength of the adsorption, but being a physisorption only, it is not energetically very demanding.

(b) Reactive adsorption, which involves a chemical reaction between organosulfur compounds and solid sorbent surface. Sulfur is usually attached to the sorbent as a sulfide. Regeneration of the sorbent can be achieved thermally, or by flushing spent sorbent with desorbent. Sulfur is usually removed as $\mathrm{H}_{2} \mathrm{~S}, \mathrm{SO}_{\mathrm{x}}$ or elemental sulfur, depending on the process and the nature of feedstock (Babich and Moulijn 2003).

A variety of sorbent materials were evaluated for the desulfurization. Among others, activated carbon, zeolites, amorphous silica-aluminas, and metal organic framework (MOF) sorbents were evaluated for desulfurization of model oils, fluid catalytic cracking feedstock, coker naphtha, and distillates (Salem 1994, 1997; Irvine et al. 1999; Brieva et al. 2010). In spite of the acceptable desulfurization degree that was achieved under mild reaction conditions in laboratory and pilot plant experiments, the performance of even the most efficient of the adsorbents is still insufficient for industrial applications.

Application to heavy oil, despite its higher sulfur content, is unpractical, due to the poor accessibility of large molecules in the narrow pores and steric hindrance that reduces adsorption effectiveness. In this respect many of the problems encountered during catalytic HDS are mirrored by adsorptive desulfurization, because both methods rely of adsorption on a solid surface.

\section{Oxidative desulfurization (ODS)}

Oxidative desulfurization, as the name implies, involves a chemical reaction between an oxidant and sulfur that facilitates desulfurization. Although we refer to ODS as if it is a single process, it invariably involves two conceptually different steps. The first step is the sulfur oxidation, which changes the nature of the sulfur compounds. The second step is the sulfur removal, which exploits the properties of the oxidized sulfur compounds (as opposed to the unoxidized sulfur compounds) to effect their removal. There are some recent review in literature dealing specifically with ODS (Anisimov and Tarakanova 2009; Campos-Martin et al. 2010; Ismagilov et al. 2011). Literally hundreds of papers on ODS appeared in the past 2 years, indicating that this is a field of considerable interest at present.

The most common industrial application of ODS, is sweetening. Sweetening is a refining process that is employed for the conversion of thiols into disulfides (Eq. 4) (Marty 2001).

$2 \mathrm{R}-\mathrm{SH}+1 / 2 \mathrm{O}_{2} \rightarrow \mathrm{R}-\mathrm{S}-\mathrm{S}-\mathrm{R}+\mathrm{H}_{2} \mathrm{O}$

Industrially, the thiols are converted in a basic medium to increase their reactivity to oxygen. For economic reasons aqueous caustic soda $(\mathrm{NaOH})$ is used as base, air is the oxidant, and a homogeneous phase catalyst is employed to increase the reaction rate. The process is selective for thiols and other classes of sulfur functionality are not converted. Sweetening is therefore not relevant to the desulfurization of heavy oil, because the thiol content of the heavy fractions is very low (Table 1). 
The type of ODS that is relevant to heavy oil conversion, is oxidation of the sulfur in sulfide and thiophenic compounds to sulfoxides (Eq. 5) and sulfones (Eq. 6) (Plesničar 1978).

$$
\begin{aligned}
& \mathrm{R}-\mathrm{S}-\mathrm{R}^{\prime}+1 / 2 \mathrm{O}_{2} \rightarrow \mathrm{R}-(\mathrm{SO})-\mathrm{R}^{\prime} \\
& \mathrm{R}-\mathrm{S}-\mathrm{R}^{\prime}+\mathrm{O}_{2} \rightarrow \mathrm{R}-\left(\mathrm{SO}_{2}\right)-\mathrm{R}^{\prime}
\end{aligned}
$$

The sulfoxides and sulfones have two properties that are different from the unoxidized sulfur compounds and that facilitate desulfurization. First, the sulfoxides and sulfones are more polar, which increases selectivity during solvent extraction. Although oxidation does not mitigate issues such as solvent loss and energy cost associated with solvent recycling, it improves the extraction selectivity. Second, the $\mathrm{C}-\mathrm{S}$ bond strength is decreased when the sulfur is oxidized (Table 4) (McMillen and Golden 1982; Herron 1988). It is therefore easier to remove the oxidized sulfur by thermal decomposition.

An important aspect of the patent literature on ODS is that it includes contributions aimed specifically at the upgrading of heavy oil. Some of the approaches that were proposed are:

(a) Oxidation in an acidic medium, particularly using hydrogen peroxide and short-chain carboxylic acids (formic or acetic). The oxidation is conducted at low temperatures, typically at $50{ }^{\circ} \mathrm{C}$ for $6 \mathrm{~h}$. Oxidation is followed by thermal after-treatment in the range $350-450{ }^{\circ} \mathrm{C}$ to rupture the $\mathrm{C}-\mathrm{S}$ bonds that have been weakened in the oxidized material. The temperature for the after-treatment is chosen so that thermal degradation of the hydrocarbons is minimized (Webster et al. 1964).

(b) Oxidation by an oxidising agent, amongst other air, at $80-180{ }^{\circ} \mathrm{C}$. Oxidation is optionally performed in the presence of a non-acidic catalyst promoted with metals from Group 5A (e.g. V) and Group 8 (e.g. Ni, Pd, Pt). The oxidation is followed by thermal treatment at above $200{ }^{\circ} \mathrm{C}$ and preferably in the range $300-400{ }^{\circ} \mathrm{C}$ to liberate sulfur

Table 4 Homolytic C-S bond dissociation energies at $25{ }^{\circ} \mathrm{C}$ for unoxidized and oxidized sulfur groups

\begin{tabular}{ll}
\hline Compound classes $^{\mathrm{a}}$ & $\begin{array}{l}\text { Bond dissociation } \\
\text { energy }\left(\mathrm{kJ} \mathrm{mol}^{-1}\right)\end{array}$ \\
\hline Unoxidized sulfur & \\
$\mathrm{CH}_{3} \mathrm{~S}-\mathrm{CH}_{3}$ & 320 \\
$\mathrm{PhS}-\mathrm{CH}_{3}$ & 290 \\
Oxidized sulfur & \\
$\mathrm{CH}_{3}\left(\mathrm{SO}_{2}-\mathrm{CH}_{3}\right.$ & 230 \\
$\mathrm{CH}_{3}\left(\mathrm{SO}_{2}\right)-\mathrm{CH}_{3}$ & 280 \\
$\mathrm{Ph}\left(\mathrm{SO}_{2}\right)-\mathrm{CH}_{3}$ & 240 \\
$\mathrm{Ph}\left(\mathrm{SO}_{2}\right)-\mathrm{Ph}$ & 290 \\
\hline
\end{tabular}

${ }^{\mathrm{a}} \mathrm{Ph}=$ Phenyl group, $-\mathrm{C}_{6} \mathrm{H}_{5}$ mainly as $\mathrm{SO}_{2}$. This step is followed by catalytic hydrodesulfurization (Ford et al. 1967).

(c) Oxidation of sulfur species to sulfur-oxygen species by contacting the material with an oxidising agent in an acidic aqueous medium. The $\mathrm{C}-\mathrm{S}$ bonds of the oxidized material are then ruptured by contacting it with a molten alkali metal hydroxide, forming water-soluble sulfur compounds. The water-soluble sulfur compounds can subsequently be separated from the hydrocarbon fraction (Wallace and Heimlich 1970).

(d) The sulfur-containing compounds are oxidized with an oxidizing agent, such as peroxide. The oxidized product is then contacted with a light paraffinic hydrocarbon solvent to recover the fraction with lower sulfur content (Cole et al. 1970). (The last step seems to be similar to asphaltene precipitation by solvent deasphalting, with the asphaltenes retaining most of the oxidized sulfur compounds).

(e) Oxidation by an oxidizing agent (e.g. hydrogen peroxide), in the presence of an acid (e.g. acetic acid) and a titanium-based catalyst. The reaction is conducted at around $50{ }^{\circ} \mathrm{C}$, although the range $20-90{ }^{\circ} \mathrm{C}$ was claimed. The process was demonstrated with model sulfur and nitrogen containing compounds and was tested with crude oil fractions. The solvent and products are afterwards separated by distillation and extraction (Litz et al. 2008, 2009).

\section{Autoxidation}

Autoxidation is a term that refers to oxidation by atmospheric oxygen, i.e. oxygen in air. An overview of the general chemistry and kinetics of sulfur autoxidation can be found in literature (Pasiuk-Bronikowska et al. 1992). In this work, the special case of autoxidation involving a catalyst or oxygen carrier will be discussed separately.

The most common description of autoxidation involves the formation of a hydroperoxide species, which is a key intermediate that is formed in situ by the oxygen. The oxidation process takes place by a free radical mechanism, which is hardly surprising since molecular oxygen $\left(\mathrm{O}_{2}\right)$ is paramagnetic and therefore effectively a diradical species. Autoxidation proceeds readily at a low temperature and typical conditions for selective autoxidation is less than $200{ }^{\circ} \mathrm{C}$ and near atmospheric pressure. More severe autoxidation is found in processes such as bitumen hardening for the production of road asphalt (Vassiliev et al. 2001).

During the autoxidation of heavy oil some sulfur is typically removed as $\mathrm{SO}_{2}$. Most of the sulfur compounds are converted into sulfoxides and sulfones, which can be separated from treated crude oil by a second step.

Heavy oil and oil sands derived bitumen has been tested at various conditions to analyze the physical and chemical 
changes after autoxidation. It was found that $150{ }^{\circ} \mathrm{C}$ is an important threshold temperature value that affects the ODS of bitumen. At $150{ }^{\circ} \mathrm{C}$, there is change in reaction order. There is a high-rate first-order autoxidation regime below $150{ }^{\circ} \mathrm{C}$ and second-order autoxidation regime at low extent of oxidation at temperatures above $150{ }^{\circ} \mathrm{C}$ (Babu and Cormack 1983). For example, compared with a straight run kerosene fraction where thiol removal increases with oxidation temperature, sulfur removal from bitumen does not monotonically increase with autoxidation temperature (Paniv et al. 2006).

During the autoxidation of crude oil, some hydrocarbon molecules can be oxidized too. Insoluble oxidation products are formed that appear as gums and sediments. The formation of gums and sediments are more when oxidizing oil sands-derived bitumen compared with lighter oil fractions (Bolshakov 2007). The parameters that affect lowtemperature oxidation of heavy oil and some of the changes that accompany autoxidation have been reported in literature (Moschopedis and Speight 1975; Noureldin et al. 1987; Xu et al. 2001; Jia et al. 2005; Javadli and De Klerk 2012).

One of the key challenges that remain in the application of autoxidation for the ODS of heavy oil is the avoidance of free radical addition reactions. These reactions result in a significant viscosity increase (Babu and Cormack 1984), which complicates transport and downstream upgrading. Nevertheless, it was demonstrated that around 46-47\% desulfurization of Cold Lake bitumen was possible with autoxidation followed by water extraction (Javadli and De Klerk 2012).

\section{Chemical oxidation}

Direct chemical oxidation by hydrogen peroxide $\left(\mathrm{H}_{2} \mathrm{O}_{2}\right)$, or by an organic hydroperoxide, is commonly found in ODS studies. The use of a peroxide species avoids the initiation period associated with the slow in situ formation of hydroperoxides by autoxidation. The sulfur-containing compounds can directly be oxidized by the hydroperoxide to yield a sulfoxide and then a sulfone (Eq. 7) (Attar and Corcoran 1978).

$$
\begin{aligned}
\mathrm{R}^{\prime}-\mathrm{S}-\mathrm{R}^{\prime \prime}+2 \mathrm{RO}_{2} \mathrm{H} \rightarrow & \mathrm{R}^{\prime}-\left(\mathrm{SO}_{2}\right)-\mathrm{R}^{\prime \prime} \\
& +2 \mathrm{ROH}, \mathrm{R}=\mathrm{H} \text { or alkyl }
\end{aligned}
$$

The sulfur oxidation mechanism is more complex than suggested by Eq. 7, since both hydrogen and oxygen transfer must take place. In protic solvents sulfur oxidation follows pseudo-second-order kinetics with respect to hydroperoxide concentration, whereas it follows thirdorder kinetics in aprotic solvents (Curci and Edwards 1970). When the oxidation is performed by a peroxy-acid, it is possible to proceed via an intermediate that does not involve a third species to enable proton transfer (Fig. 5)
(Plesničar 1978; Curci and Edwards 1970). The suggested use of hydrogen peroxide in combination with carboxylic acids for the chemical oxidation of sulfur is therefore understandable.

However, the reaction stoichiometry demonstrates that even if the oxidation of the sulfur is selective, two moles of peroxide are required for every sulfur atom that is oxidized to a sulfone group. In practice some peroxides selfdecompose to yield $\mathrm{O}_{2}$ (Eq. 8) and do not oxidize sulfur atoms, making chemical oxidation with peroxides costly.

$\mathrm{H}_{2} \mathrm{O}_{2} \rightarrow 1 / 2 \mathrm{O}_{2}+\mathrm{H}_{2} \mathrm{O}$

Chemical oxidants other than peroxides have also been investigated for heavy oil oxidation. The oxidants include nitric acid, potassium dichromate, potassium permanganate, and ozone (Moschopedis and Speight 1971a, b; Escobar et al. 2001).

\section{Catalytic oxidation}

Within the broad class of catalytic oxidation, a number of approaches can be distinguished. First, there is the use of oxidation catalysts that reduce the energy barrier of oxidation by facilitating the oxidation reaction itself on the catalytically active surface. Second, there are materials that serve as oxygen carriers and are more active oxidation agents than oxygen. Third, there are catalysts that facilitate the decomposition of hydroperoxides, thereby accelerating the propagation step in the oxidation reaction.

Catalytic oxidation is well researched, e.g. (Sheldon and Kochi 1981). However, applying heterogeneous catalysts for the oxidation of heavy oil suffers from the same drawbacks as the application of heterogeneous catalysts for the HDS of heavy oil, which was mentioned before. Catalyst accessibility and fouling are serious obstacles. Homogeneous catalysts do not have the same drawback, but cannot be easily recovered from heavy oil, which creates its own set of problems. Although there is little scope for the application oxidation catalysts that require heavy oil adsorption, other forms of catalysis are possible.

Oxygen carriers can selectively oxidize sulfur compounds in crude oil and can be regenerated by molecular oxygen. Depending on the nature of the carrier, it can be viewed as a form of catalytic oxidation. It is a two-step process, with oxidation of sulfur compounds by the oxygen carrier (Eq. 9) being followed by regeneration of the oxygen carrier (Eq. 10) (Attar and Corcoran 1978):

$$
\begin{aligned}
& \text { Oxidation : }(\text { Carrier })-\mathrm{O}_{2}+\mathrm{R}^{\prime}-\mathrm{S}-\mathrm{R}^{\prime \prime} \\
& \qquad \mathrm{R}^{\prime}-\left(\mathrm{SO}_{2}\right)-\mathrm{R}^{\prime \prime}+(\text { Carrier }) \\
& \text { Regeneration : (Carrier) }+\mathrm{O}_{2} \rightarrow(\text { Carrier })-\mathrm{O}_{2}
\end{aligned}
$$

Oxidation processes can be accelerated by low concentrations of metal ions, which in turn can accelerate 
Fig. 5 Dibenzothiophene oxidation by a peroxy acid, which is capable of intramolecular proton transfer
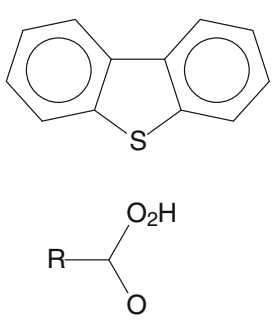

ODS. Increased oxidation rates have been reported in the presence of catalysts such as copper(II) phenolates, Fe(III) salts like Fe(III) nitrate and Fe(III) bromide, NiMo catalysts, cobalt salts like $\mathrm{Co}$ (II) acetate, $\mathrm{Co}$ (II) chloride and $\mathrm{Co}$ (II) bromide, the metals from Group 5A and Group 8 of the periodic table or their salts and oxides (e.g. Pt, Pd, Ni, V) and organoiron catalysts like $\mathrm{Fe}$ (III) acetylacetonate, $\mathrm{Fe}(\mathrm{III})$ ethylhexanoate, and ferrocenyl methyl ketone (Varnakova et al. 1985; Ma et al. 2007; Selvavathi et al. 2008; Murata et al. 2004; Ford et al. 1967; Trost et al. 1991; Field and Lawson 1958). These metal ions can, if need be, heterogenized by being placed on suitable materials (e.g. alumina, soda lime, active carbon) to improve recoverability, but at the expense of decreased catalyst accessibility.

In the presence of the metal ions, the required temperature for desulfurization becomes lower. The metals catalyze the decomposition of organic hydroperoxides, which are the primary intermediates in autoxidation. This reduces the induction time, which is the time required between the start of autoxidation and when a significant increase in $\mathrm{O}_{2}$ consumption is seen. Depending on the feedstock, oxidant and catalyst, the temperature is usually within the range between 80 and $180{ }^{\circ} \mathrm{C}$ for the oxidation step and the required oxygen amount is 1-6 active oxygen atoms in the oxidizing agent per each sulfur atom in feedstock (Ford et al. 1967). Oxidation can proceed at milder conditions too. For example, it was reported that in the presence of $\mathrm{Fe}(\mathrm{III})$ salts oxidative desulfurization of thiophenic sulfur compounds by conversion into corresponding sulfoxides and sulfones occurred at $25{ }^{\circ} \mathrm{C}$ (Ma et al. 2007).

\section{Photochemical oxidation}

Photochemical oxidation reportedly has a high efficiency and requires mild reaction conditions (Zhao et al. 2008). The method involves two steps: first, sulfur compounds are transferred from the oil into a polar solvent and then the transfer is followed by photooxidation or photodecomposition under UV irradiation. The oxidation chemistry is similar to the other oxidation methods, but instead of thermal energy, energy is supplied by light.

Various methods have been developed for different types of light oil and organosulfur compounds such as

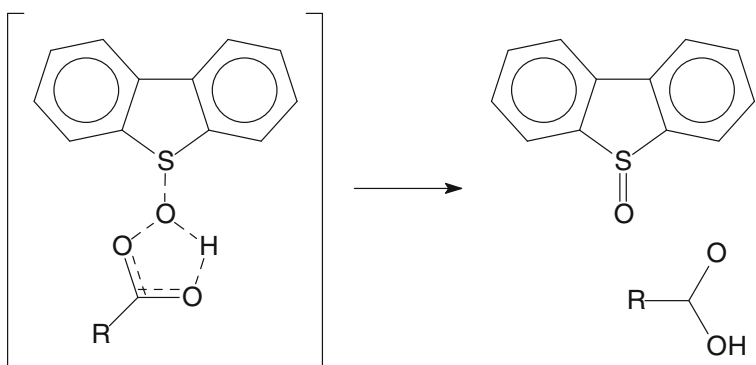

thiophene, benzothiophene, and dibenzothiophene (Zhao et al. 2008; Shiraishi et al. 2001; Aladin et al. 2003; Zhao et al. 2008). Although good sulfur removal ( 90\%) was achieved during experiments with model light oils, the initial extractive step precludes application to heavy oil.

\section{Ultrasound oxidation}

Ultrasound-assisted oxidative desulfurization provides energy for the oxidation process by ultrasound, but it does not affect the oxidation chemistry. The process can be described as follows: The raw materials and oxidants are mixed with surfactants and water in a reactor to make a mixture of water and the organic medium. Under the influence of ultrasound, the mixture is stratified easily into aqueous and organic phases, and the local temperature and pressure of the mixture increases rapidly in a short period of time (Zhang et al. 2009). At the same time, free radicals are generated with the aid of an oxidant and as a result, the sulfur compounds are oxidized to sulfoxides, sulfones, and sulfates, which are transferred to the aqueous phase. After solvent extraction the sulfones and sulfates can be removed from the system.

This method has been applied to remove sulfur compounds from diesel fuel in the presence of hydrogen peroxide: ultrasound irradiation is an energy source and phosphoric and acetic acids are catalysts (Sun et al. 2008). Similar experiments have been conducted with model oil (dibenzothiophene dissolved in toluene) (Mei et al. 2003).

In another study ultrasound-assisted oxidative desulfurization followed by extraction has been applied to various diesel fuels in the presence of hydrogen peroxide with a transition metal complex and quaternary ammonium salts as catalyst. It was found that desulfurization exceeds $95 \%$ in a short period of time under ambient conditions (Wan and Yen 2007).

Although ultrasound-assisted oxidative desulfurization provides a high level of desulfurization, it has some drawbacks. The use of hydrogen peroxide as an oxidant is expensive. There are scale-up limitations related to the ultrasound-producing device. Moreover, hydrogen peroxide can cause the formation of oil-water emulsions. Mass 
transfer is also an issue and providing adequate oil-water contact requires extended mixing time (Zhang et al. 2009).

The above-mentioned drawbacks would be exacerbated when applied to heavy oil.

\section{Biodesulfurization (BDS)}

Biodesulfurization takes place at low temperatures and pressure in the presence of microorganisms that are capable of metabolizing sulfur compounds. It is possible to desulfurize crude oil directly by selecting appropriate microbial species (Mehran et al. 2007).

There are potential benefits to BDS, such as lower capital and operation costs. It has been reported that BDS requires approximately two times less capital and $15 \%$ less operating cost in comparison with traditional HDS (Pacheco et al. 1999; Linguist and Pacheco 1999; Kaufman et al. 1998).

The longevity of microorganisms in BDS processes used to be short, around 1-2 days, but this has been extended to 8-16 days (200-400 h) (Pacheco et al. 1999). There were also advances made in reactor design. Reduced mass transport limitations enabled higher volumetric flow rates and led to improvement in the efficiency of BDS. The use of staging and air sparging (in the case of aerobic conversion) with a lower water-to-oil ratio enabled conversion in smaller reactors. These advances unfortunately also came with a tradeoff. As the concentration of microorganisms increase, separation becomes more difficult and additional equipment to break the oil-water emulsion is required (Pacheco et al. 1999).

Currently, BDS is not commercially employed for crude oil desulfurization for several reasons, but mainly the logistics of sanitary handling, shipment, storage and use of microorganisms within the production field or refinery environment.

\section{Aerobic biodesulfurization}

Aerobic BDS was proposed as an alternative to hydrodesulfurization of crude oil. It was reported that BDS by Pantoea agglomerans D23W3 resulted in 61\% sulfur removal from a light crude oil that originally contained $0.4 \%$ sulfur and $63 \%$ sulfur removal from a heavy crude oil that originally contained $1.9 \%$ sulfur. It was found that integrated methods performed better than just BDS. By combining ODS with BDS it was possible to achieve $91 \%$ sulfur removal from heavy oil (Agarwal and Sharma 2010).

In the temperature range $30-50{ }^{\circ} \mathrm{C}$, Alcaligenes xylosoxidans is very effective and selective for BDS. Members of the genus Alcaligenes actively break down $\mathrm{C}-\mathrm{S}-\mathrm{C}$ bonds in complex organosulfur compounds to produce inorganic sulfur compounds (Fig. 6) (Ranson and Rivas 2002). Under the aerobic conditions, oxidative desulfurization produces sulfates. The sulfates thus formed are water-soluble and can be removed with the aqueous phase. Some BDS to produce $\mathrm{H}_{2} \mathrm{~S}$ also takes place.

Other microorganisms that have been identified for BDS include Rhodococcus erythropolis D-1 and IGTS8, Rhodococcus ECRD-1 ATCC 55301, B1, SY1, UM3 and UM9, Agrobacterium MC501, Mycobacterium G3, Gordona GYKS1, Klebsiella, Xanthomonas, Nocardia globelula, thermophilic Paenibacillus, and some Cytochrome P450 species. Reported desulfurization yields are $30-70 \%$ from middle distillates, $40-90 \%$ from diesel fuels, $65-70 \%$ from hydrotreated diesel, 20-60\% from light gas oil, 75-90\% from cracked stocks, and 20-60\% from crude oil (Kaufman et al. 1998; Shong 1999; Atlas et al. 1998; Monticello 1998).

Depending on the species there may be specificity for particular sulfur compounds and metabolic pathways are not necessarily restricted to sulfur (Kirkwood et al. 2005, 2007a, b). Desulfurization comes with an associated carbon cost. The viability of BDS depends both on the desulfurization efficiency and the selectivity of sulfur over carbon. If carbon metabolism is high it becomes important to harvest the microorganisms to recover some of the lost carbon.

\section{Anaerobic biodesulfurization}

The main advantage of anaerobic desulfurization processes over aerobic desulfurization is that oxidation of hydrocarbons to undesired compounds, such as colored and gumforming products, is negligible (McFarland 1999).

A sulfate-reducing bacterium (SRB), Desulfovibrio desulfuricans M6, was used to desulfurize model sulfur compounds and crude oils of different origins (Kim et al. 1990, 1995; Lizama et al. 1995). It was shown that more sulfur can be removed from heavier fractions of petroleum than the total crude and the lighter fractions. Some sulfur compounds were removed completely; while others were not affected, i.e. aromatic sulfur compounds were more susceptible to the reductive degradation by the bacterium in comparison to aliphatic sulfur compounds. Within the class of thiophenic compounds it was shown that Desulfovibrio desulfuricans M6 converted $96 \%$ of the benzothiophene and $42 \%$ of the dibenzothiophene (Kim et al. 1990).

Other microorganisms did not perform as well. Desulfomicrobium scambium and Desulfovibrio long-reachii were able to convert only $10 \%$ of the dibenzothiophene in a model mixture with kerosene. Other sulfate-reducing bacteria from the Desulfovibrio genus isolated from oil field production facilities, such as Desulfovibrio vulgaris and Desulfovibrio desulfuricans, also performed poorly. Experiments under well-controlled anaerobic conditions did not demonstrate significant desulfurization of 
Fig. 6 Selective aerobic biodesulfurization by members of the Alcaligenes genus as illustrated by the desulfurization of dibenzothiophene.

Unselective bio-conversion leads to substantial carbon oxidation. (Main species shown; reactions are not balanced)
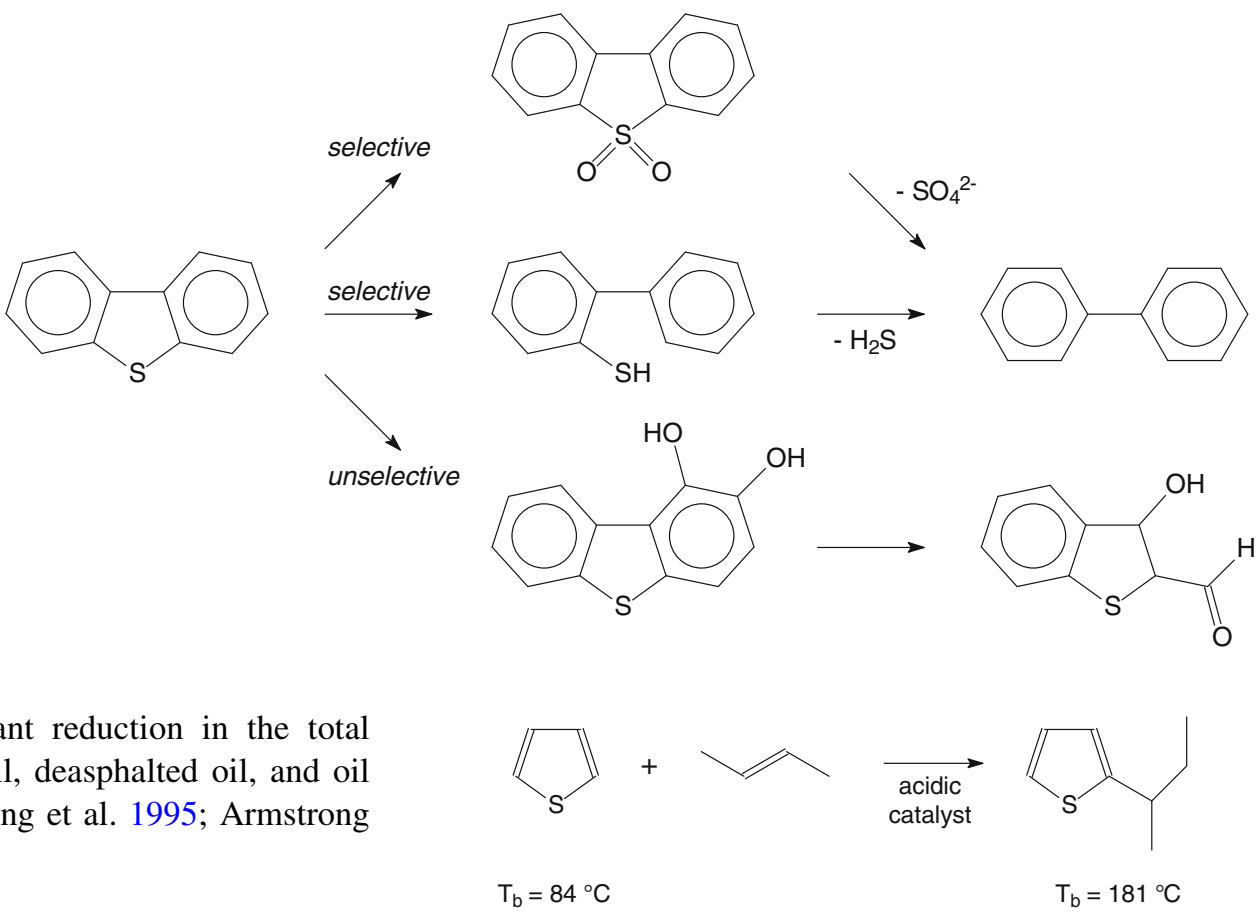

Fig. 7 Alkylation-based desulfurization illustrated by the acid catalyzed alkylation of thiophene with 2-butene to increase the boiling point temperature $\left(T_{\mathrm{b}}\right)$ of the product

\section{S-alkylation}

Thiophenic compounds react with iodomethane $\left(\mathrm{CH}_{3} \mathrm{I}\right)$ in the presence of silver tetrafluoroborate $\left(\mathrm{Ag}-\mathrm{BF}_{4}\right)$ to produce S-methylatedsulfonium salts (Fig. 8) (Shiraishi et al. 2001a, b). These alkylated sulfur compounds can then be removed from the oil as precipitates, thereby effectively desulfurizing the oil. It does not require separation by distillation as in the case of C-alkylation, which simplifies the separation. However, alkylation takes place competitively with aromatic hydrocarbons, eroding its applicability to oils that are aromatic rich. Since heavy oils tend to be aromatic, this technology is not suitable for the desulfurization of heavy oils.

\section{Chlorinolysis-based desulfurization}

Chlorinolysis involves the scission of $\mathrm{C}-\mathrm{S}$ and $\mathrm{S}-\mathrm{S}$ bonds through the action of chlorine (Eqs. 11, 12) (Kalvinskas et al. 1982).

$$
\begin{aligned}
& \mathrm{R}-\mathrm{S}-\mathrm{R}^{\prime}+\mathrm{Cl}_{2} \rightarrow \mathrm{R}-\mathrm{S}-\mathrm{Cl}+\mathrm{R}^{\prime}-\mathrm{Cl} \\
& \mathrm{R}-\mathrm{S}-\mathrm{S}-\mathrm{R}^{\prime}+\mathrm{Cl}_{2} \rightarrow \mathrm{R}-\mathrm{S}-\mathrm{Cl}+\mathrm{R}^{\prime}-\mathrm{S}-\mathrm{Cl}
\end{aligned}
$$

The process is performed at low temperatures $\left(25-80{ }^{\circ} \mathrm{C}\right)$ and near-atmospheric pressure, and requires a short residence time. It requires good mixing of oil and the chlorine gas and it requires equipment having adequate of heavy oil. 
corrosion resistance to chlorine. At moderate temperature and in the presence of water, chlorinolysis can be followed by hydrolysis and oxidation of the sulfur to produce sulfates. A 3:10 volumetric ratio of water to oil works best (Kalvinskas et al. 1982). This is followed by aqueous and caustic washes to remove the sulfur and chlorine containing by-products. Around $75-90 \%$ of total sulfur can be removed in an hour.

Although the chlorinolysis-based desulfurization method has not been tested with heavy oil or oil sands-derived bitumen, in theory it has some potential to be applied to bitumen production at steam-assisted gravity drainage (SAGD) sites. In this way the reaction is conducted within the oil sands formation, avoiding much of the cost associated with chlorineresistant materials. However, there is a safety risk associated with such operation and the volume of chlorine required is considerable.

\section{Supercritical water-based desulfurization}

The effect of supercritical water (SCW) on desulfurization of oil is marginal (Vogelaar et al. 1999). The purpose of using SCW (critical point of water: $374{ }^{\circ} \mathrm{C}$ and $22.1 \mathrm{MPa}$ ) as reaction medium is to break $\mathrm{C}-\mathrm{S}$ bonds. According to experiments that were carried out at $400{ }^{\circ} \mathrm{C}$ and $25 \mathrm{MPa}$, aromatic sulfur compounds do not react in SCW, but SCW can convert non-aromatic sulfur compounds. Similar findings were reported by Katritzky et al. (1992a, b, 1994, 1997), who conducted an extensive study on the conversion of sulfur-containing compounds in sub- and supercritical water. It was found that thermal free radical-based conversion dominated and not conversion by aqueous ionic pathways.

Some benefit of using SCW was reported for the in situ generation of $\mathrm{H}_{2}$ (Adschiri et al. 1998), as well as using SCW as medium for hydrotreating Athabasca bitumen (Piskorz et al. 1996). These are indirect benefits. The best desulfurization results with SCW were achieved when conventional hydrotreating catalysts were added to the system, which facilitated HDS (Adschiri et al. 1998). The experimental results show that SCW alone cannot remove sulfur appreciably, but in combination with $\mathrm{H}_{2}$ and conventional HDS catalysts, sulfur and metal impurities can be removed.

There are some reports dealing with the conversion of heavy oil in SCW. Pease River and Cold Lake bitumens behaved somewhat differently, but at $375{ }^{\circ} \mathrm{C}$, little conversion was found in the absence of water and in the presence SCW (Clark and Kirk 1994). In the presence of a catalyst desulfurization took place, mainly by the formation of sulfur-rich precipitates. The product contained a higher content of asphaltenes than the feed, except when $\mathrm{H}_{2}$ was co-fed.

More optimistic results can be found in the patent literature. For example, it was reported that when heavy hydrocarbons, such as shale oil, were converted in a SCW and light olefin mixture, the liquid yield from heavy hydrocarbon cracking was improved (Paspek 1984). However, the overwhelming body of evidence suggests that SCW itself does not react to any appreciable degree with the heavy oil. The main advantages of SCW water are dilution, precipitation of sulfur-rich species, and $\mathrm{H}_{2}$ production by water gas shift. SCW is therefore not really responsible for desulfurization.

\section{Discussion}

The objective of the review was to evaluate desulfurization strategies for heavy oil and not desulfurization in general. There are some important differences between heavy oils and lighter refinery streams that determine the desulfurization technologies that are viable. Generally, as the material that must be desulfurized becomes heavier

(a) The concentration of sulfur containing species increases.

(b) More of the sulfur is contained in thiophenic structures.

(c) There is an increase in fouling species, such as metals and coke precursors.

(d) The density, molecular mass, boiling-point temperature, and viscosity increase.

(e) Increasing asphalthene content and precipitation tendency are observed.

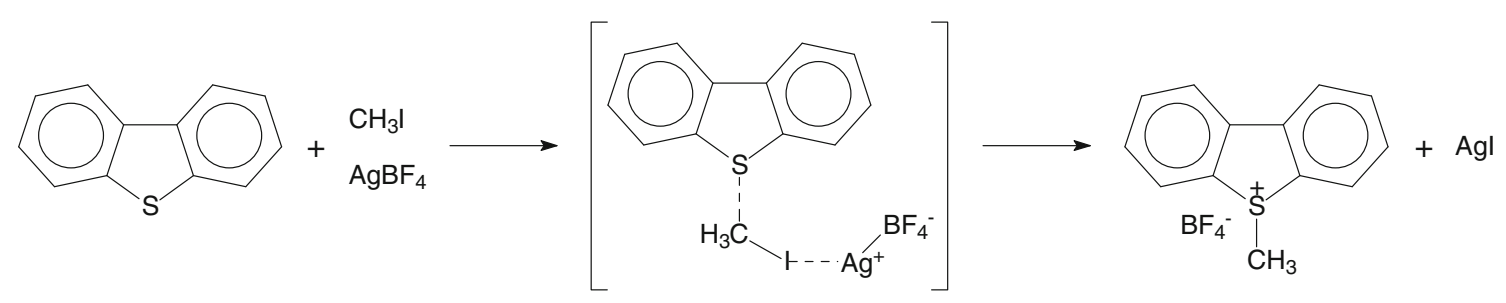

Fig. 8 S-Alkylation of thiophenic compounds by iodomethane and silver tetrafluoroborate to produce S-alkylsulfonium salts 
Critical evaluation of strategies for desulfurization of heavy oil

The physical properties and fouling nature of heavy oil undermine the efficiency of any desulfurization strategy that depends on a solid absorbent or catalyst to perform primary desulfurization of the feed. This does not imply that such technologies cannot be used. Industrially, hydroprocessing is one of the key desulfurization technologies for heavy oil; however, in application it is very different from hydroprocessing of lighter oils (Ancheyta et al. 2005). The service life and per pass desulfurization conversion is lower for heavy oils and the application of fixed bed hydroprocessing is restricted by the fouling nature of the feed (Rana et al. 2007). The same fate befalls adsorptive desulfurization. Accessibility and desorption of heavy molecules from solid surfaces are inherently problematic. The prognosis for a breakthrough increase in desulfurization efficiency of heavy oil using either hydrodesulfurization, or adsorption desulfurization on its own is not good.

Extractive desulfurization becomes increasingly difficult and unselective as the heaviness of the oil increases. Solvent loss and recovery are important detractors when desulfurizing heavy oil. The sulfur compounds are high boiling and the heavy oil is viscous. It is unlikely that a solvent can be found that will be sulfur-selective based purely on a physical extraction. It is anticipated that any breakthrough in extractive desulfurization of heavy oil will, out of necessity, be in reactive extractive desulfurization, i.e. a solvent that chemically reacts with sulfur in sulfurcontaining compounds to produce a separate phase. Even so, this does not eliminate the problems associated with solvent recovery, which must still be addressed.

Technology for oxidative desulfurization involves two steps. These steps must be considered separately.

The oxidative step requires an oxidant that is at least stoichiometrically consumed. Many studies employ chemical oxidation, usually with hydrogen peroxide and often in combination with an organic acid. This is not a viable strategy for heavy oil desulfurization. The mass of hydrogen peroxide that is required for heavy oil desulfurization is too much (Fig. 9). Even if ideal stoichiometric oxidation was possible, around $0.1 \mathrm{~kg} \mathrm{H}_{2} \mathrm{O}_{2}$ per $\mathrm{kg}$ of bitumen $(5 \% \mathrm{~S})$ would be required to convert the all the sulfur into sulfones. Any oxidative route for desulfurization of heavy oil will be viable only if it employs a cheap and readily available oxidant, such as air. Autoxidation of heavy oil may lead to a breakthrough in desulfurization, whereas chemical oxidation and catalytic oxidation are less likely to yield viable processes. Photochemical activation and ultrasound are only alternative pathways to thermal energy to drive the oxidation reaction. Whether this is industrially desirable is not clear, considering that oxidation requires mild conditions $\left(<200{ }^{\circ} \mathrm{C}\right.$ and near atmospheric pressure). In both instances the oxidant must still be supplied and selecting an alternative energy source will not yield a breakthrough in desulfurization.

Removing the oxidized sulfur compounds from the heavy oil requires an extractive or decomposition step. The viability of extractive desulfurization has already been discussed. Decomposition has clear advantages over extraction, even though it requires processing at more severe conditions. Industrially, thermal processing of heavy oil is already practiced on large scale and desulfurization of oxidized heavy oil by thermal decomposition removes the sulfur as $\mathrm{SO}_{2}$. The use of catalysts (acidic and basic) to assist desulfurization of the oxidized product led only to a minor increase in desulfurization (Sundaraman et al. 2009). Irrespective, it is important to retain the hydrocarbon portion of sulfur-containing compounds. Even when the oxidized sulfur is removed by extraction or precipitation, the sulfur is still associated with a significant amount of hydrocarbon material. Thermal treatment is therefore still desirable in order to liberate the sulfur as $\mathrm{SO}_{2}$. Even though thermal processing of oil predates other conversion processes, there may be unexplored opportunities for heavy oil thermal treatment in combination with oxidation.

The combination of autoxidation and thermal decomposition for the ODS of heavy oil seems likely to be a viable pathway for a breakthrough in desulfurization. However, this would require a strategy to limit free radical addition and hardening of the bitumen due to the oxidation, which is a formidable obstacle.

In nature there are many examples of microorganisms that metabolize sulfur. The challenge for biodesulfurization is to find appropriate microorganisms. It is desirable that the microorganisms have a high metabolic selectivity for sulfur in general. Establishing and maintaining a viable culture that is capable of a reasonable desulfurization rate

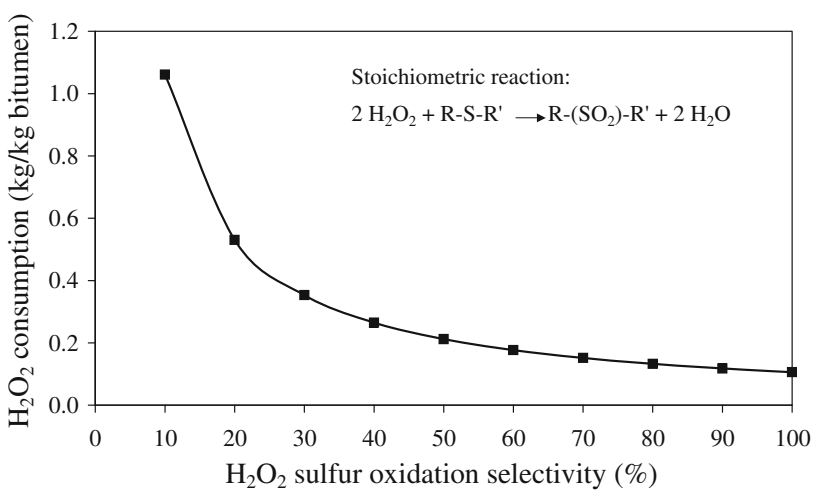

Fig. 9 Hydrogen peroxide $\left(\mathrm{H}_{2} \mathrm{O}_{2}\right)$ consumption for desulfurization of heavy oil containing $5 \%$ sulfur as a function of the selectivity of $\mathrm{H}_{2} \mathrm{O}_{2}$ for sulfur oxidation to sulfones 
is challenging. Heavy oil is viscous and immiscible with water and BDS is inherently transport limited. Yet, there are opportunities for breakthrough desulfurization technology, despite some of the technical challenges associated with bio-conversion in general.

Alkylation and chlorinolysis-based desulfurization strategies suffer from the same drawback as ODS with hydrogen peroxide (Fig. 9). The mass of chemicals required for desulfurization is considerable, even if a high selectivity can be achieved. In addition to this, alkylation also has other technical issues that were discussed before, which preclude application to heavy oil.

Supercritical water does not result in desulfurization (Vogelaar et al. 1999; Clark and Kirk 1994). Desulfurization reported in conjunction with SCW can be traced to other removal mechanisms, mainly HDS.

Synergetic desulfurization strategies for heavy oil

The oxidation of sulfur in sulfur containing compounds not only provides an oxidative pathway for sulfur removal, but also produces a product that can more efficiently be desulfurized in combination with other technologies. Three specific examples of synergy were noted:

(a) Using sulfur oxidation as a pretreatment step for BDS resulted in better desulfurization than just BDS on its own (Agarwal and Sharma 2010). Oxidation increases the polarity of the sulfur-containing species, which changes the partitioning behavior in contact with water. The solubility of the oxidized sulfur species in water is increased relative to the unoxidized sulfur and hydrocarbon species. This has productivity and selectivity advantages for BDS. One of the metabolic pathways for BDS is also improved by preoxidizing the sulfur.

(b) Sulfur oxidation increases the selectivity for desulfurization during subsequent thermal treatment of the oxidized heavy oil (Sundaraman et al. 2009).

(c) Oxidation of thiophenic sulfur takes place readily. Thiophenic sulfur is activated for oxidation and liquidphase oxidation can readily convert sulfur species that are sterically hindered for adsorption on a catalytic surface. ODS (e.g. oxidation followed by thermal treatment) can therefore desulfurize species that are difficult to remove by HDS. There is possible synergy in combining HDS and ODS, i.e. mild HDS to remove the thiols and sulfides and ODS to remove the thiophenic compounds.

\section{Conclusions}

Various methods were suggested for the desulfurization of oils and refinery streams. These strategies include hydrodesulfurization, extractive desulfurization, oxidative desulfurization, biodesulfurization, alkylation-based desulfurization, chlorinolysis-based desulfurization, and desulfurization using supercritical water. Despite the variety of methods reported in literature, few of the strategies are viable for the desulfurization of heavy oil. This is mainly due to the properties of the heavy oil, such as high sulfur content, high viscosity, high boiling point, and refractory nature of the sulfur compounds.

The following specific observations were made based on a review of desulfurization literature and the applicability of different desulfurization strategies for heavy oil:

(a) The fouling nature, high viscosity, and bulkiness of the molecules in heavy oil undermine the efficiency of processes that require a solid material, as catalyst or adsorbent.

(b) The high boiling nature, high viscosity, and complexity of heavy oil make it difficult to employ separation strategies that rely on selective extraction and distillation. This holds true even when the sulfur molecules are selectively converted by alkylation, oxidation or chlorinolysis prior to separation.

(c) Biodesulfurization may lead to successful desulfurization, but there are technical obstacles related to the refractory nature of the sulfur molecules that must be metabolized, high viscosity, and the complexity of the heavy oil. Microorganisms with high sulfur specificity are required, as well as ways to overcome the transport limitations.

(d) Selective reactive conversion of sulfur compounds that requires a stoichiometric reagent that cannot be supplied at low cost and in bulk, has little chance of leading to an economically viable desulfurization process. Heavy oil has a high sulfur content and the amount of reagent required for desulfurization is very high. Industrially $\mathrm{H}_{2}$ is employed, which is typically produced from $\mathrm{CH}_{4}$ and $\mathrm{H}_{2} \mathrm{O}$. Chemicals that are more expensive on a molar basis are likely too expensive. This disqualifies alkylation, chlorinolysis, and many of the chemical oxidation processes for desulfurization.

(e) Supercritical water on its own does not lead to desulfurization. Desulfurization that was reported in conjunction with supercritical water can be ascribed to other forms of desulfurization.

(f) Autoxidation (oxidation with air as oxidant) is a viable desulfurization strategy for heavy oil. Autoxidation itself leads to little desulfurization and it must be used in combination with a sulfur removal step. Thermal decomposition seems to be the most viable desulfurization strategy for heavy oil after oxidation.

(g) Synergetic combinations involving oxidation with biodesulfurization, thermal processing, and hydrodesulfurization were noted.

Acknowledgments This investigation was funded by the Centre for Oilsands Innovation (COSI-2010-07) and permission to publish the results is appreciated. 
Open Access This article is distributed under the terms of the Creative Commons Attribution License which permits any use, distribution, and reproduction in any medium, provided the original author(s) and the source are credited.

\section{References}

Adschiri T, Shibata R, Sato T, Watanabe M, Arai K (1998) Catalytic hydrodesulphurization of dibenzothiophene through partial oxidation and a water-gas shift reaction in supercritical water. Ind Eng Chem Res 37:2634-2638

Agarwal P, Sharma DK (2010) Comparative studies on the biodesulfurization of crude oil with other desulfurization techniques and deep desulfurization through integrated processes. Energy Fuels 24:518-524

Aladin I, Shen BS, Zhou W (2003) Desulfurization of FCC gasoline by solvent extraction and photooxidation. Petrol Sci Technol 21:1555-1573

Ancheyta J, Rana MS, Furimsky E (2005) Hydroprocessing of heavy petroleum feeds: tutorial. Catal Today 109:3-15

Anisimov AV, Tarakanova AV (2009) Oxidative desulfurization of hydrocarbon raw materials. Russ J Gen Chem 79:1264-1273

Arias M, Laurenti D, Geantet C, Vrinat M, Hideyuki I, Yoshimura Y (2008) Gasoline desulfurization by catalytic alkylation over silica-supported heteropolyacids: from model reaction to real feed conversion. Catal Today 130:190-194

Armstrong SM, Sankey BM, Voordouw G (1995) Conversion of dibenzothiophene to biphenyl by sulphate-reducing bacteria isolated from oil field production facilities. Biotechnol Lett 17:1133-1137

Armstrong SM, Sankey BM, Voordouw G (1997) Evaluation of sulphate reducing bacteria for desulfurizing bitumen or its fractions. Fuel 76:223-227

Atlas RM, Boron DJ, Deever WR, Johnson AR, McFarland BL, Meyer JA (1998) Biodesulfurization of gasoline: a technology roadmap. Coordinating research Council, Project E-7c, Atlanta Georgia, pp 1-82

Attar A, Corcoran WH (1978) Desulfurization of organic sulphur compounds by selective oxidation. 1. Regenerable and nonregenerable oxygen carriers. Ind Eng Chem Prod Res Dev 17:102-109

Babich IV, Moulijn JA (2003) Science and technology of novel processes for deep desulfurization of oil refinery streams: a review. Fuel 82:607-631

Babu DR, Cormack DE (1983) Low temperature oxidation of Athabasca bitumen. Can J Chem Eng 61:575-580

Babu DR, Cormack DE (1984) Effect of oxidation on the viscosity of Athabasca bitumen. Can J Chem Eng 62:562-564

Bataille F, Lemberton JL, Michaud P, Pérot G, Vrinat M, Lemaire M, Schulz E, Breysse M, Kasztelan S (2000) Alkyldibenzothiophenes hydrodesulfurization: promoter effect, reactivity, and reaction mechanism. J Catal 191:409-422

Bolshakov GF (2007) The effect of organic sulphur compounds on oxidation process of hydrocarbon fuels. J Sulfur Chem 7:379-392

Bosmann A, Datsevich L, Jess A, Lauter A, Schmitz C, Wasserscheid P (2001) Deep desulfurization of diesel fuel by extraction with ionic liquids. Chem Commun 7:2494-2495

Brieva GB, Campos-Martin JM, Al-Zahrani SM, Fierro JLG (2010) Removal of refractory organic sulphur compounds in fossil fuels using MOF sorbents. Glob NEST J 12:296-304

Brons G, Yu JM (1995) Solvent deasphalting effects on whole Cold Lake bitumen. Energy Fuels 9:641-647
Campos-Martin JM, Capel-Sanchez MC, Perez-Presas P, Fierro JLG (2010) Oxidative processes of desulfurization of liquid fuels. J Chem Technol Biotechnol 85:879-890

Clark PD, Kirk MJ (1994) Studies on the upgrading of bituminous oils with water and transition metal catalysts. Energy Fuels 8:380-387

Cole EL, Wilson RF, Herbstman S (1970) Desulfurization of a heavy hydrocarbon fraction. Patent US 3,551,328 (Texaco)

Corma A, Martínez C, Ketley G, Blair G (2001) On the mechanism of sulfur removal during catalytic cracking. Appl Catal A 208:135-152

Curci R, Edwards JO (1970) Peroxide reaction mechanisms: polar. In: Swern D (ed) Organic peroxides, vol 1. Wiley, New York, pp 199-264

Donald FS, Schaub TM, Sunghwan K, Rodgers RP, Rahimi P, Teclemariam A, Marshall AG (2008) Characterization of acidic species in Athabasca bitumen and bitumen heavy vacuum gas oil by negative-ion ESI FT-ICR MS with and without acid-ion exchange resin prefractionation. Energy Fuels 22:2372-2378

Escobar G, Patino P, Acevedo S, Escobar O, Ranaudo MA, Pereira JC (2001) Interfacial properties of the products of ozonolysis of Hamaca crude oil. Petrol Sci Technol 19:107-118

Esser J, Wasserscheid P, Jess A (2004) Deep desulfurization of oil refinery streams by extraction with ionic liquids. Green Chem 6:316-322

Field L, Lawson JE (1958) Organic Disulfides and Related Substances, I. Oxidation of thiols to disulfides with lead tetraacetate, oxidation of thiols to disulfides. J Am Chem Soc 80:838-841

Ford JF, Rayne TA, Adlington DG (1967) Desulphurization of hydrocarbons using oxidative and hydro-treatments. Patent US 3,341,448 (British petroleum)

Ford JF, Rayne TA, Adlington DG (1967) Desulphurization of hydrocarbons using oxidative and hydro-treatments. Patent US $3,341,448$

Gray MR (2010) Fundamentals of oil sands upgrading. Custom Courseware, Department of Chemical and Materials Engineering, University of Alberta, Edmonton

Gray MR, Jokuty P, Yeniova H, Nazarewycz L, Wanke SE, Achia U, Krzywicki A, Sanford EC, Sy OKY (1991) The relationship between chemical structure and reactivity of Alberta bitumens. Can J Chem Eng 69:833-843

Gray MR, Ayasse AR, Chan EW, Veljkovic M (1995) Kinetics of hydrodesulfurization of thiophenic and sulfide sulfur in Athabasca bitumen. Energy Fuels 9:500-506

Haung C, Chen B, Zhang J, Liu Z, Li Y (2004) Desulfurization of gasoline by extraction with new ionic liquids. Energy Fuels 46:111-150

Heinrich G, Kasztelaan S (2001) Hydrotreating. In: Leprince P (ed) Petroleum Refining. Conversion Processes, vol 3. Editions Technip, Paris, pp 533-573

Herron JT (1988) Thermochemistry of sulfoxides and sulfones. In: Patai S, Rappoport Z, Stirling C (eds) The chemistry of sulphones and sulphoxides. Wiley, Chichester, pp 95-106

Ho TC (2004) Deep HDS of diesel fuel: chemistry and catalysis. Catal Today 98:3-18

Hochgesang FP (1952) In: Hartough HD (ed) Thiophene and its derivatives. Interscience, New York, $\mathrm{p} 86$

Irvine RL, Benson BA, Varraveto DM (1999) IRVAD ${ }^{\mathrm{TM}}$ Processlow cost breakthrough for low sulphur gasoline. In: NPRA 1999 Annual Meeting, San Antonio, Texas, 21-23 March 1999, Paper AM-99-42

Ismagilov Z, Yashnik S, Kerzhentsev M, Parmon V, Bourane A, AlShahrani FM, Hajji AA, Koseoglu OR (2011) Oxidative desulfurization of hydrocarbon fuels. Catal Rev Sci Eng 53:199-255

Ito E, Van Veen JAR (2006) On novel processes for removing sulphur from refinery streams. Catal Today 116:446-460

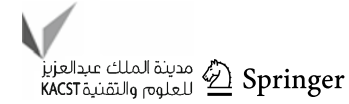


Izumi F, Tetsuo A (1995) Process for recovering organic sulfur compounds from fuel oil. U.S. Patent 5,753,102

Javadli R, De Klerk A (2012) Desulfurization of heavy oil-oxidative desulfurization (ODS) as potential upgrading pathway for oil sands derived bitumen. Energy Fuels 26:594-602

Jia N, Moore RG, Mehta SA, Fraassen KV, Ursenbach MG, Zalewski E (2005) Compositional changes for Athabasca bitumen in the presence of oxygen under low temperature conditions. J Can Petrol Tech 44:51-57

Kalvinskas JJ, Pasadena GC, Hsu LC, Ernest JB, Ana S (1982) Crude Oil Desulfurization. Patent US 4,310, 049

Katritzky AR, Balasubramanian M, Siskin M (1992a) Aqueous hightemperature chemistry of carbo- and heterocycles: 17 . Thiophene, tetrahydrothiophene, 2-methylthiophene, 2,5-dimethylthiophene, benzothiophene and dibenzothiophene. Energy Fuels 6:431-438

Katritzky AR, Lapucha AR, Greenhill JV, Siskin M (1992b) Aqueous high-temperature chemistry of carbo-and heterocycles: 13 . Sulfides and disulfides. Energy Fuels 4:562-571

Katritzky AR, Barcock RA, Balasubramanian M, Greenhill JV, Siskin M, Olmstead WN (1994) Aqueous high temperature chemistry of carbo- and heterocycles: 21. Reactions of sulfur-containing compounds in supercritical water at 460 C. Energy Fuels 8:498-506

Katritzky AR, Barcock RA, Ignatchenko ES, Allin SM, Siskin M, Hudson CW (1997) Aqueous high-temperature chemistry of carbo- and heterocycles: 18. Reactions of aryl sulfoxides and sulfones in sub- and supercritical water at $200-460^{\circ} \mathrm{C}$. Energy Fuels 11:150-159

Kaufman EN, Harkins JB, Borole AP (1998) Comparison of batchstirred and electrospray reactors for biodesulfurization of dibenzothiophene in crude oil and hydrocarbon feedstocks. Appl Biochem Biotechnol 73:127-144

Kim HY, Kim TS, Kim BH (1990) Degradation of organic compounds and the reduction of dibenzothiophene to biphenyl and hydrogen sulphide by Desulfovibrio desulfuricans M6. Biotechnol Lett 12:761-764

Kim BH, Kim HY, Kim TS, Park DH (1995) Selectivity of desulfurization activity of Desulfovibrio desulfuricans M6 on different petroleum products. Fuel Process Technol 43:87-94

Kirkwood KM, Ebert S, Foght JM, Fedorak PM, Gray MR (2005) Bacterial biodegradation of aliphatic sulfides under aerobic carbon- or sulfur-limited growth conditions. J Appl Microbiol 99:1444-1454

Kirkwood KM, Foght JM, Gray MR (2007a) Selectivity among organic sulfur compounds in one- and two-liquid-phase cultures of Rhodococcus sp. strain JVH1. Biodegradation 18:473-480

Kirkwood KM, Andersson JT, Fedorak PM, Foght JM, Gray MR (2007b) Sulfur from benzothiophene and alkylbenzothiophenes supports growth of Rhodococcus sp. strain JVH1. Biodegradation 18:541-547

Lecrenay E, Sakanishi K, Mochida I (1997) Catalytic hydrodesulfurization of gas oil and model sulphur compounds over commercial and laboratory-made CoMo and NiMo catalysts: activity and reaction scheme. Catal Today 39:13-20

Linguist LK, Pacheco MA (1999) Enzyme-based diesel desulfurization process offers energy, $\mathrm{CO}_{2}$ advantages. Oil Gas J 97(8):45-48

Litz KE, Dutta P, Lewis S, Rossetti M, Pawlson J, Ullman T, Amaratunga G, Vreeland JM, Jordan TM (2008) Product containing monomer and polymers of titanyls and methods for making same. Patent application WO2008/153633 (Auterra)

Litz KE, Jordan TM, Rossetti M, Loughran AJ, Vreeland JM (2009) Sulfoxidation catalysts and methods and systems of using same. Patent application WO2009/120238 (Applied nanoworks)
Liu P, Shi Q, Chung KH, Zhang Y, Pan N, Zhao S, Xu C (2010) Molecular characterization of sulfur compounds in Venezuela crude oil and its SARA fractions by electrospray ionization Fourier transform ion cyclotron resonance mass spectrometry. Energy Fuels 24:5089-5096

Lizama HM, Wilkins LA, Scott TC (1995) Dibenzothiophene sulphur can serve as sole electron acceptor during growth by sulphatereducing bacteria. Biotechnol Lett 17:113-116

Ma X, Zhou A, Song C (2007) A novel method for oxidative desulfurization of liquid hydrocarbon fuels based on catalytic oxidation using molecular oxygen coupled with selective adsorption. Catal Today 123:276-284

Marty C (2001) White product refining by sweetening. In: Leprince P (ed) Petroleum refining. Conversion processes, vol. 3. Editions Technip, Paris, pp 503-532

McFarland BL (1999) Biodesulfurization. Curr Opin Microbiol 2:257-264

McMillen DF, Golden DM (1982) Hydrocarbon bond dissociation energies. Ann Rev Phys Chem 33:493-532

Mehran S, Amarjeet B, Argyrios M (2007) Biodesulfurization of refractory organic sulphur compounds in fossil fuels. Biotechnol Adv 25:570-596

Mei H, Mei BW, Yen TF (2003) A new method for obtaining ultralow sulphur diesel fuel via ultrasound assisted oxidative desulfurization. Fuel 82:405-414

Monticello DJ (1998) Riding the fossil fuel biodesulfurization wave. Chem. Technol 28:38-45

Moschopedis SE, Speight JG (1971a) Water-soluble derivatives of Athabasca asphaltenes. Fuel 50:34-40

Moschopedis SE, Speight JG (1971b) Oxidative degradation of Athabasca asphaltenes. Fuel 50:211-217

Moschopedis SE, Speight JG (1975) Oxidation of a bitumen. Fuel $54: 210-212$

Murata S, Murata K, Kidena K, Nomura M (2004) A novel oxidative desulfurization system for diesel fuels with molecular oxygen in the presence of cobalt catalysts and aldehydes. Energy Fuels 18:116-121

Noureldin NA, Lee DG, Mourits FM, Jha KN (1987) Chemical changes accompanying the low temperature oxidation of heavy oil. AOSTRA J Res 3:155-161

Pacheco MA, Lange EA, Pienkos PT, Yu LQ, Rouse MP, Lin Q, Linguist LK (1999) Recent advances in biodesulfurization of diesel fuel. In: NPRA AM-99-27, 1999, National Petrochemical and Refiners Association, Annual Meeting, 21-23 March, San Antonio, Texas, pp 1-26

Panda SK, Andersson JT, Schrader W (2009) Characterization of supercomplex crude oil mixtures: what is really in there? Angew Chem Int Ed 48:1788-1791

Paniv PM, Pysh'ev SV, Gaivanovich VI, Lazorko OI (2006) Current problems, nontraditional technologies, noncatalytic oxidation desulfurization of the kerosene cut. Chem Tech Fuels Oils 42:159-166

Pasiuk-Bronikowska W, Ziajka J, Bronikowski T (1992) Autoxidation of sulphur compounds. Ellis Horwood, New York

Paspek SC (1984) Upgrading heavy hydrocarbons with supercritical water and light olefins. Patent US 4,483,761

Paulino F (1995) Process for the removal of sulfur from petroleum fractions. U.S. Patent 5,582,714

Pawelec B, Navarro RM, Campos-Martin JM, Fierro JLG (2011) Towards near zero-sulfur liquid fuels: a perspective review. Catal Sci Technol 1:23-42

Piskorz J, Radlein D, Majerski P, Donald SS (1996) Hydrotreating of heavy hydrocarbon oils in supercritical fluids. Patent US $5,496,464$

Plesničar B (1978) Oxidation with peroxy acids and other peroxides. In: Trahanovsky WS (ed) Oxidation in organic chemistry. Part C 
(Organic chemistry; A series of monographs, vol 5). Academic Press, New York, pp 211-294

Purcell JM, Juyal P, Kim DG, Rodgers RP, Hendrickson CL, Marshall AG (2007) Sulphur speciation in petroleum: atmospheric pressure photoionization or chemical derivatization and electrospray ionization Fourier transform ion cyclotron resonance mass spectrometry. Energy Fuels 21:2869-2874

Rana MS, Sámano V, Ancheyta J, Diaz JAI (2007) A review of recent advances on processing technologies for upgrading of heavy oils and residua. Fuel 86:1216-1231

Ranson I, Rivas CM (2002) Biodesulfurization of hydrocarbons. Patent US 6,808,919 B2

Salem ABSH (1994) Naphtha desulfurization by adsorption. Ind Eng Chem Res 33:336-340

Salem ABSH (1997) Removal of sulphur compounds from naphtha solutions using solid adsorbents. Chem Eng Technol 20:342-347

Santana RC, Do PT, Santikunaporn M, Alvarez WE, Taylor JD, Sughrue EL, Resasco DE (2006) Evaluation of different reaction strategies for the improvement of cetane number in diesel fuels. Fuel 85:643-656

Seeberger A, Jess A (2010) Desulfurization of diesel oil by selective oxidation and extraction of sulphur compounds by ionic liquids: a contribution to a competitive process design. Green Chem 12:602-608

Selvavathi V, Meenakshisundaram A, Sairam B, Sivasankar B (2008) Kinetics of oxidative desulfurization of sulphur compounds in diesel fuel. Petrol Sci Technol 26:208-216

Sheldon RA, Kochi JK (1981) Metal-catalysed oxidations of organic compounds. Academic Press, New York

Shi Q, Pan N, Liu P, Keng H, Zhao CS, Zhang Y, Xu C (2010) Characterization of sulphur compounds in oilsands bitumen by methylation followed by positive-ion electrospray ionization and Fourier transform ion cyclotron resonance mass spectrometry. Energy Fuels 24:3014-3019

Shiraishi Y, Hirai T, Komasawa I (2001a) A deep desulfurization process for light oil by photochemical reaction in an organic two-phase liquid-liquid extraction system. Ind Eng Chem Res 37:203-211

Shiraishi Y, Taki Y, Hirai T, Komasawa I (2001b) A novel desulfurization process for fuel oils based on the formation and subsequent precipitation of S-alkylsulfonium salts. 1. Light oil feedstocks. Ind Eng Chem Res 40:1213-1224

Shiraishi Y, Tachibana K, Taki Y, Hirai T, Komasawa I (2001c) A novel desulfurization process for fuel oils based on the formation and subsequent precipitation of S-alkylsulfonium salts. 2 . Catalytic-cracked gasoline. Ind Eng Chem Res 40:1225-1233

Shong RG (1999) Bioprocessing of Crude Oil. ACS Natl Meet Proc 44:1-9
Song C (2002) New approaches to deep desulfurization for ultra-clean gasoline and diesel fuels: an overview. Prepr Pap Am Chem Soc Div Fuel Chem 47(2):438-444

Sudipa MK, Mullins OC, Ralston CY, Pareis C (1999) Sulphur characterization in asphaltenes, resin, and oil fractions of two crude oils. Prepr Pap Am Chem Soc Div Fuel Chem 44(4): 763-767

Sun MZ, Zhao DZ, Sun WW (2008) Study on the oxidative desulfurization of diesel fuel with power ultrasound. Chem Adh 30:65-68

Sundaraman R, Peduzzi E, Song C (2009) Catalytic cracking of oxidized sulfur compounds in gas oil stream. Prepr Pap Am Chem Soc Div Fuel Chem 54(2):954-955

Topsøe H, Clausen BS, Massoth FE (1996) Hydrotreating catalysis. Sci Tech 11:1-310

Trost BM, Fleming I, Ley SV (1991) Comprehensive organic synthesis, selectivity. Strat Eff Mod Org Chem 7:758-769

Varnakova GV, Mashkina AV, Masagutov RM, Sharipov AK, Kirik NP, Zagryatskaya LM, Suleimanova ZA (1985) Oxidation of organic sulphides and sulfoxides by oxygen in the presence of copper complexes. React Kinet Catal Lett 29:33-39

Vassiliev NY, Davison RR, Williamson SA, Glover CJ (2001) Air blowing of supercritical asphalt fractions. Ind Eng Chem Res 40:1773-1780

Vogelaar BM, Makkee M, Moulijn JA (1999) Applicability of supercritical water as a reaction medium for desulfurization and demetallisation of gasoil. Fuel Process Technol 61:265-277

Wallace TJ, Heimlich BN (1970) Desulfurization of petroleum residua. Patent US 3,505,210 (Esso research and engineering)

Wan MW, Yen TF (2007) Enhanced efficiency of tetraoctylammonium fluoride applied to ultrasound-assisted oxidative desulfurization (UAOD) process. Appl Catal A 319:237-245

Weast RC (1988) CRC handbook of chemistry and physics. CRC Press, Boca Raton

Webster AB, Small NJH, Rigby R (1964) Desulfurization of heavy oils. Patent US 3,163,593 (Shell)

$\mathrm{Xu}$ HH, Okazawa NE, Moore RG, Mehta SA, Laureshen MG, Mallory DG (2001) In situ upgrading of heavy oil. J Can Petrol Tech 40:45-53

Zhang G, Yu F, Wang R (2009) Research advances in oxidative desulfurization technologies for the production of low sulphur fuel oils. Petrol Coal 51:196-207

Zhao DS, Tang LF, Sun ZM (2008a) Study on photosensitized oxidative desulfurization of thiophene by riboflavin. J Fuel Chem Technol 36:161-164

Zhao DS, Liu R, Wang J, Liu B (2008b) Photochemical oxidationionic liquid extraction coupling technique in deep desulfurization of light oil. Energy Fuels 22:1100-1103 